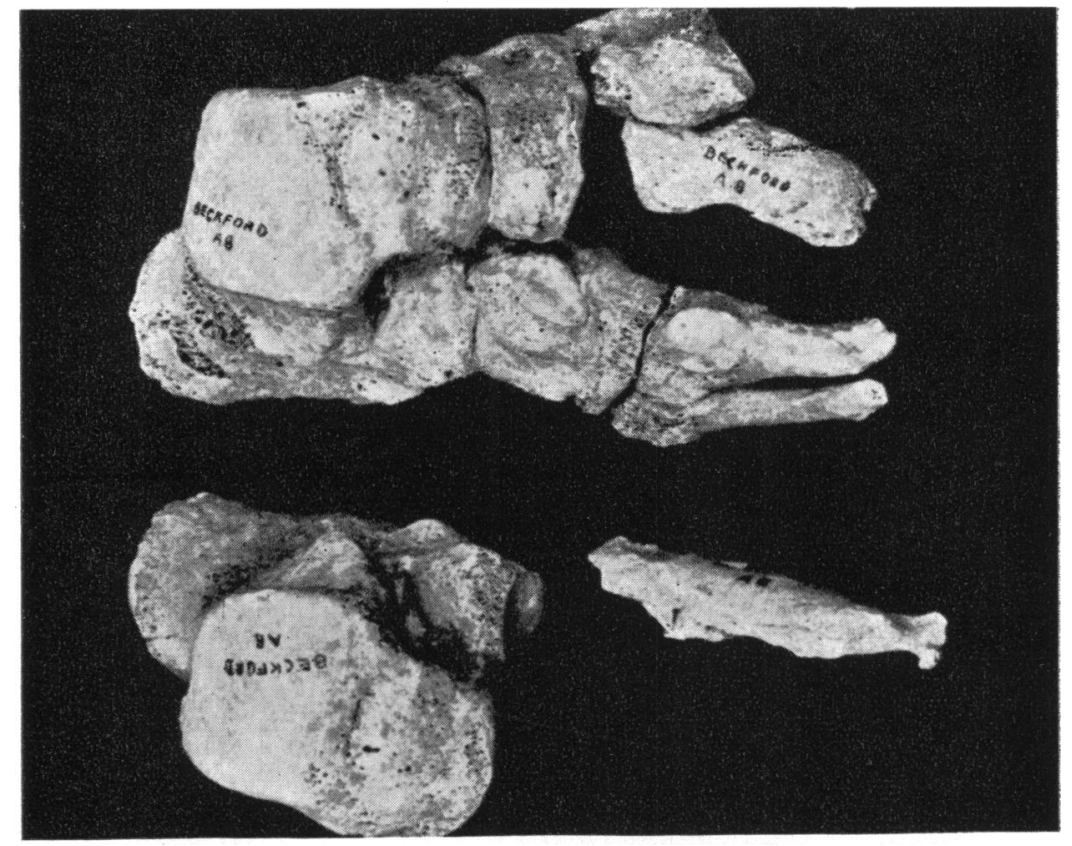

:

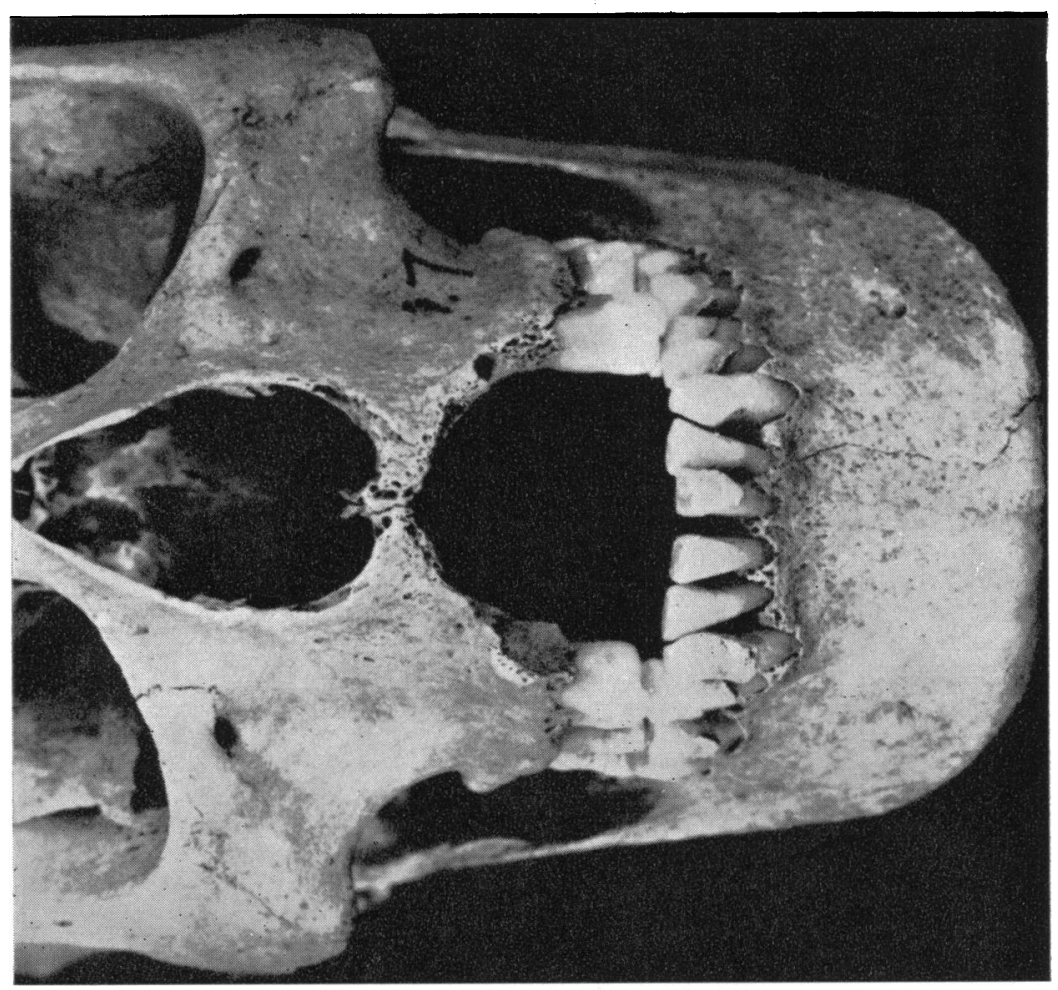

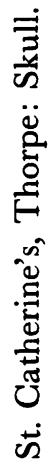




\section{A POSSIBLE CASE OF LEPROSY FROM A SAXON GEMETERY AT BECKFORD}

by

\section{GALVIN WELLS}

IN an interesting article in an earlier issue of this journal, D. R. Brothwell ${ }^{1}$ described two pathological skulls which he diagnosed as leprosy. One came from a post-Conquest burial ground at Scarborough, the other was the cranial cast of Robert the Bruce (1274-1329). Both examples do, indeed, suggest leprosy though neither, I think, is completely typical of it.

The Bruce skull (apart from the uncertainty of the casting) shows an extensive loss of alveolar tissue which seems to vary somewhat from that now usually seen in leprosy. We must remember, however, that many diseases have shown remarkable changes in their manifestations at different times and in different parts of the world. We have little precise knowledge of the earlier clinical picture of leprosy and it is possible and even likely that it differed considerably from what we see today. $2,3,4,5$

There is in the Castle Museum, Norwich, a Late Saxon skull from St. Catherine's, Thorpe, near Norwich (Accession number ${ }_{15} 5.953 \mathrm{P}_{7}$ ), with a maxillary defect very similar to that shown in the Bruce cast. The four incisors are missing and there is an area of irregular resorption of the bone extending back across the hard palate. I have always thought that this was probably traumatic, not due to any battle wound from the weapons currently in use (it is a female skull, aged thirty to thirty-five) but the result of some simple domestic accident such as we still see commonly enough. In this case the initial trauma would have caused the loss of the teeth and fracture of the alveolus, and the change in the bone of the palate would have resulted from a secondary infective process. Another possibility is that this is the result of a malignant process such as a neoplasm of the lip and $I$ think that this is a diagnosis that might well account for the changes in the skull of Robert the Bruce. Of one thing we may be sure: in early historic and mediaeval times the frequency of wrong diagnosis where leprosy was concerned must have been extremely high and there is no certainty that the contemporaries of King Robert would have accurately distinguished a fungating epithelioma from leprous infection. We must not put too much reliance, therefore, on the historical tradition that he was a leper.

The Scarborough skull is that of a young adolescent and is perhaps a more convincing example of the disease. The margins of the piriform fossa are affected by a resorptive process and there is some slight osteoporosis of the palate. The picture resembles quite closely leprosy as we see it today but various other possibilities will occur to anyone with clinical experience. When I first saw it I found it was almost identical with a case of lupus vulgaris with secondary 


\section{Wells}

bone infection that eventually came to me in the post-mortem room. And I have a record of a case of glanders which was strikingly similar in pathological appearance to this Scarborough skull. Secondary infection following nasolabial trauma, especially in marasmic or under-nourished individuals, will also occasionally produce comparable bone changes.

It seems advisable, therefore, to be cautious in accepting either of these interesting specimens as being lepers though Mr. Brothwell is to be thanked for drawing our attention to the possibility.

For many years I have at times been tempted to diagnose leprosy but until now I have always felt that the various possible examples I have seen have been too ambiguous to warrant description as such. The case I now want to describe comes from a sixth century Saxon burial ground at Beckford, Gloucestershire. It is a male, aged thirty to thirty-five years. His general skeletal and muscular development was good. The body has been excavated with meticulous care and down to the feet is substantially complete except for some rib fragments, four carpals and seven phalanges of the hands. Almost all the bones are in excellent condition, unaffected by soil action.

The chief pathological parts are the feet, of which the following bones are present:

Left Foot: talus, calcaneus and $5^{\text {th }}$ metatarsal.

Right Foot: talus, calcaneus, navicular, cuboid, ist cuneiform, 2nd, $4^{\text {th }}$ and $5^{\text {th }}$ metatarsals.

There is evidence of a low-grade osteitis and slight deformity of the tarsal bones. The metatarsals are grossly diseased. They show complete destruction of their heads as a result of a chronic infective process. Their bases are distorted and their shafts taper to thin points. Marked resorption of the bones has occurred but craggy and irregular proliferation is also present, especially round their bases. No trace of the phalanges was found in the grave and it is likely that together with the heads of the metatarsals they were completely destroyed by the disease. The appearance of these feet well illustrates the chronicity of the infection. There is no trace of sinus or sequestrum formation in any bone. The leg bones, especially the fibulae, show definite but slight superficial osteitic change. This is probably the result of a secondary septic infection, perhaps terminal, rather than a direct result of the leprous condition. Both tibiae are similarly affected. Also they both have small squatting facets at the distal articular surface but these are less pronounced than are usually found in the population of this and similar burial grounds. The femora are normal as is the rest of the skeleton with the possible exception of the frontal bone. This shows a small patch of superficial erosion in the region of the glabella and above the medial part of the right orbit. It is ill-defined and may be no more than postinhumation erosion. In view of its doubtfully pathological nature I have ignored it in making the diagnosis.

I have not, however, decided that this is a case of leprosy without having considered numerous other possibilities. Gangrene of the extremities may occur as a primary condition in several diseases and as a secondary condition of

$$
3^{84}
$$




\section{A Possible Case of Leprosy from a Saxon Cemetery at Beckford}

infective or circulatory origin in several more. From the possible diagnoses some were more easily eliminated than others. The common gangrene of senile arteriosclerosis could be excluded on account of the subject's age. The well preserved vertebrae showed no trace of spina bifida. The normal hands (including six terminal and fifteen other phalanges) made syringomyelia improbable. Thrombo-angiitis obliterans, Buerger's disease, Raynaud's disease, syphilis, tuberculosis, osteomyelitis, actinomycosis and traumatic amputation were reviewed and for various reasons rejected, together with such exotics as elephantiasis, Madura foot, etc. Diabetes was carefully considered and similarly rejected. Frostbite needed some thought but the balance of probability was firmly against it. I felt that the 'runner-up' diagnosis could well have been ergotism, but the case must be reviewed against its background: it is a solitary example from a cemetery of otherwise unaffected individuals, whereas if ergotism occurs at all it is likely to be at least locally epidemic. Also England has always been remarkably free from the high continental incidence of this condition and several centuries were to elapse before there was real evidence for it in this country.

Apart from these generally negative reasons for excluding other diseases we are left with the firm fact that these feet are absolutely typical of advanced leprosy. Despite their Early Saxon date they could be used to illustrate a modern textbook of pathology.

A fairly common feature of leprous invasion of the feet is that on radiological examination it is found that the finer trabeculae are broken down and disappear and are in part replaced by fewer but coarser ones. The present specimen shows, perhaps, some evidence that this change is occurring. At any rate the trabeculae are clear and stout and there is nothing in the X-ray appearance that runs counter to the diagnosis suggested.

We need not be disturbed by the fact that this body was found in a general burial ground. Public health edicts were no doubt but feebly developed in sixth century Britain and I do not know of any evidence to support the suggestion that segregation of burial for lepers was prescribed at that period. Finally it is perhaps worth noting that two dogs about the size of small terriers were buried with this man.

In view of the total evidence available, positive and negative, macroscopic and radiological, I feel that I can tentatively offer this case as being true leprosy and, as far as I know, the earliest British example to be described.

\section{ACKNOWLEDGMENTS}

I wish to thank the excavator, Miss V. I. Evison, and the Ministry of Works for permission to publish this case. Dr. Kenneth Oakley of the British Museum (Nat. Hist.) and Mr. Rainbird Clarke, Curator, Norwich Museums, for allowing me to see the Scarborough and St. Catherine's skulls respectively. To Dr. Brian Maxwell I am indebted for his very fine radiographs and finally I must thank Dr. Morgan Hall who made a sporting, albeit unsuccessful, attempt to identify the Bacillus leprae from various parts of the specimen. 


\section{News, Notes and Queries}

\section{REFERENCES}

I. BRothWeLL, D. R. (1958). Evidence of leprosy in British archaeological material. Med. Hist., 2, 287-91.

2. Møller-Ghristensen, V. (1953). Ten lepers from Naestved in Denmark. Copenhagen: Danish Science Press.

3. - Bakke, S. N., Melsom, R. S. and WaAler, E. (i952). Changes in the anterior nasal spine and the alveolar process of the maxillary bone in leprosy. Internat. 7. Leprosy, 20, 335-40.

4. - and FABER, B. (1952). Leprous changes in a material of Mediaeval skeletons from the St. Georges Court, Naestved. Acta Radiologica, 37, 308-1 7 .

5. - ( $196 \mathrm{I})$. Bone Changes in Leprosy. Copenhagen: Munksgaard.

\section{News, Notes and Queries}

\section{A POPULAR TREATISE ON TINEA GAPITIS, BY J. A. WELCH I 837}

THE accompanying illustration shows the intriguing frontispiece of a book entitled $A$ Popular Treatise on Tinea Capitis or Ringworm with a classification of the forms under which it manifests itself, a brief analysis of the theory of inflammation and infection and a description of a Medicated Steam Bath invented by the author for the treatment and cure of diseases of the Scalp by I. A. Welch, M.R.C.S., L.S.A., published in London. There is no date on the title page but the preface is dated 1837. The author's initials are given elsewhere in the book as J.A.

The book is flamboyantly dedicated to Sir Benjamin Brodie.

My dear Sir,

On the receipt of the last proof-sheet of the pages explanatory of my practical views in the treatment of TINEA CAPITIs, I hesitated, even upon the threshold of publication, convinced, that an unremitting attention to my private practice in a path hitherto comparatively untrodden, must ultimately obtain me a professional distinction to which I had not courage to think that my public claims as an author would ever advance me. The arrival of your kind letter from Paris has fixed my wavering purpose, and attached a value, even in my own estimation, to a literary effort honoured by the approval of Sir Benjamin Brodie.

Mystery, my dear sir, in the profession of any art or science, is but another term for weakness or ignorance; and though it may appear unnecessary for an author to disclaim empiricism, of whose work you have accepted the dedication, yet, in justice to so distinguished a Member of the Profession as yourself, I deem it my duty implicitly to state, anticipating the acknowledgement in the body of my work, that the mode of applying the local means acknowledged by the best authorities as essential to the treatment of Porrigo, in its various forms, through the medium of a vaporous agent, is the chief claim to novelty in the system of,

My dear sir,

Yours, very gratefully, J. A. WELCH

The first part of the text is without interest. The illustrations are coloured and crude. It is in the final section that the interest in the book lies for it $3^{86}$ 